\title{
Spheno-Orbital Meningiomas: Optimizing Visual Outcome
}

\author{
Sudha Menon ${ }^{1}$ Sandesh $\mathrm{O}^{2}$ Debish Anand ${ }^{2}$ Girish Menon ${ }^{2} \odot$ \\ ${ }^{1}$ Department of Ophthalmology, Kasturba Medical College, \\ Manipal, India \\ ${ }^{2}$ Department of Neurosurgery, Kasturba Medical College, \\ Manipal, India

\begin{abstract}
Address for correspondence Girish Menon, MCh, DNB, Department of Neurosurgery, Kasturba Medical College , Manipal 576104, India

(e-mail: girish.menon@manipal.edu).
\end{abstract}

J Neurosci Rural Pract:2020;11:385-394

\begin{abstract}
Background Spheno-orbital meningiomas (SOMs) constitute a rare cause for orbital proptosis and visual impairment. This study aims to share our outcome experience with regard to vision and exophthalmos following the surgical management of 17 patients with SOM.

Methods Retrospective analysis of the case records of all surgically treated SOMs in the last 10 years. Exophthalmos index (EI) was calculated based on preoperative magnetic resonance imaging/computed tomography imaging. Vision was assessed using the Snellen's chart and Goldman's perimeter. Orbital volume was calculated using three-dimensional volume rendering assisted region-of-interest computation. Preoperative duration of symptoms and extent of surgery were the other predictors analyzed.

Results Patients' age ranged from 17 to 72 years (mean, $50.57 \mathrm{y}$; median, 50.0 years). Women represented 13 (76.4\%) of the entire study group. Proptosis (14/17; 82.4\%) and visual impairment $(14 / 17 ; 82.3 \%)$ were the two most common presenting complaints followed by headache $(12 / 17 ; 70.1 \%)$. Gross total resection (GTR) was achieved in only 2 of the 17 patients (11.8\%). Majority of the tumors were benign World Health Organization Grade I meningiomas (14/17; 84\%). Mean follow-up time for the entire cohort was 56 months. Postoperatively, proptosis improved in nine (64.3\%) and remained static in the rest five (35.7\%) of patients. Four patients $(28.6 \%)$ improved in vision following surgery. Vision remained static in eight patients (57.1\%). Vision deteriorated in two (14.3\%) patients who had severe preoperative visual deficits. New onset oculomotor palsy, trigeminal dysfunction, and mechanical ocular motility restriction were noticed in three (17.6\%), two (11.2\%), and six (35.3\%) patients, respectively. The mean preoperative orbital volume was $21.68 \pm 3.2 \mathrm{~cm}^{3}$ and the mean postoperative orbital volume was $23.72 \pm 3.4 \mathrm{~cm}^{3}$. Orbital volume was inversely related to El. Optic canal (OC) deroofing and extensive orbital wall decompression facilitated visual improvement and proptosis reduction. None of the variables including orbital volume proved to be statistically significant in predicting outcome.

Keywords

- orbit

- exophthalmos

- meningiomas

- sphenoid

- optic

Conclusion SOMs constitute a rare subgroup of skull base meningiomas that pose considerable surgical challenges. A surgical strategy aimed at safe maximal resection rather than aggressive GTR provides favorable outcome with less morbidity. Adequate bony decompression of the orbital walls and OC provides satisfactory improvements in proptosis and vision. Residual disease is common, but the risk of symptomatic recurrence is low especially when combined with adjuvant radiotherapy. Visual outcome is likely to be poor in patients presenting with severely compromised vision.
\end{abstract}

License terms

(1) (1) $\odot \circledast$ 


\section{Introduction}

Spheno-orbital meningiomas (SOMs) that account for 4 to $9 \%$ of all intracranial meningiomas represent a complex subgroup of skull base tumors that characteristically present with proptosis and visual deficits. ${ }^{1,2}$ SOMs are distinct from other types of sphenoid wing meningiomas in that the tumor characteristically has two components-a en plaque type of meningioma associated with hyperostosis involving the bone around the orbit and sphenoid wing. Published reports on the ophthalmological outcome following surgery for SOM are limited. This article aims to share our experience in the surgical management of these difficult orbital tumors with special focus on improvement in vision and exophthalmos. The influence of orbital volume assessment on exophthalmos was also analyzed.

\section{Materials and Methods}

Meningiomas with an orbital component and extensive hyperostosis involving the sphenoid wing and the orbit were included in the study (-Figs. 1 and 2 ). Patient charts and neuroimaging were reviewed retrospectively to identify demographics and clinical details. All patients underwent detailed neuro-ophthalmological evaluations before the surgery. Visual acuity (VA) was evaluated using the Snellen chart, and visual field (VF) was measured using the Humphrey and Goldman automated perimetry. Preoperative visual function was divided into three categories: normal (6/6 with intact VF), mildly impaired (6/9-6/30 with or without VF loss), or severely impaired (6/60 or worse). Preoperative exophthalmos was measured radiologically by using the exophthalmos index (EI)

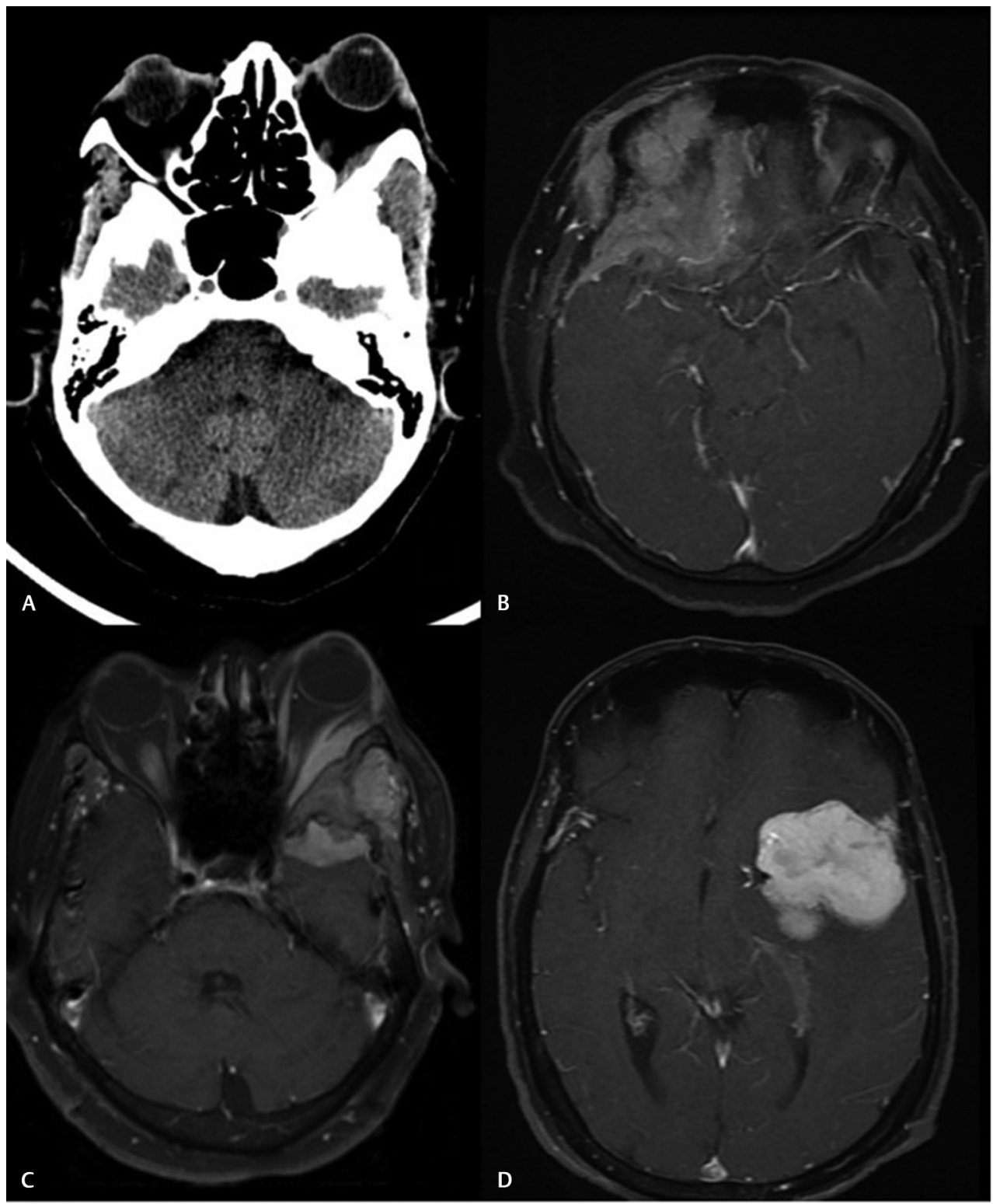

Fig. 1 Radiological features characteristic of a spheno-orbital meningioma. (A) Computed tomography scan showing extensive hyperostosis of the sphenoid wing. (B) Magnetic resonance imaging (MRI) axial contrast images showing en plaque dural extension of the tumor along the basifrontal region. (C) MRI axial contrast images of the orbit showing intraorbital extension of the tumor. (D) Intracranial extension that may or may not be seen in all cases. 


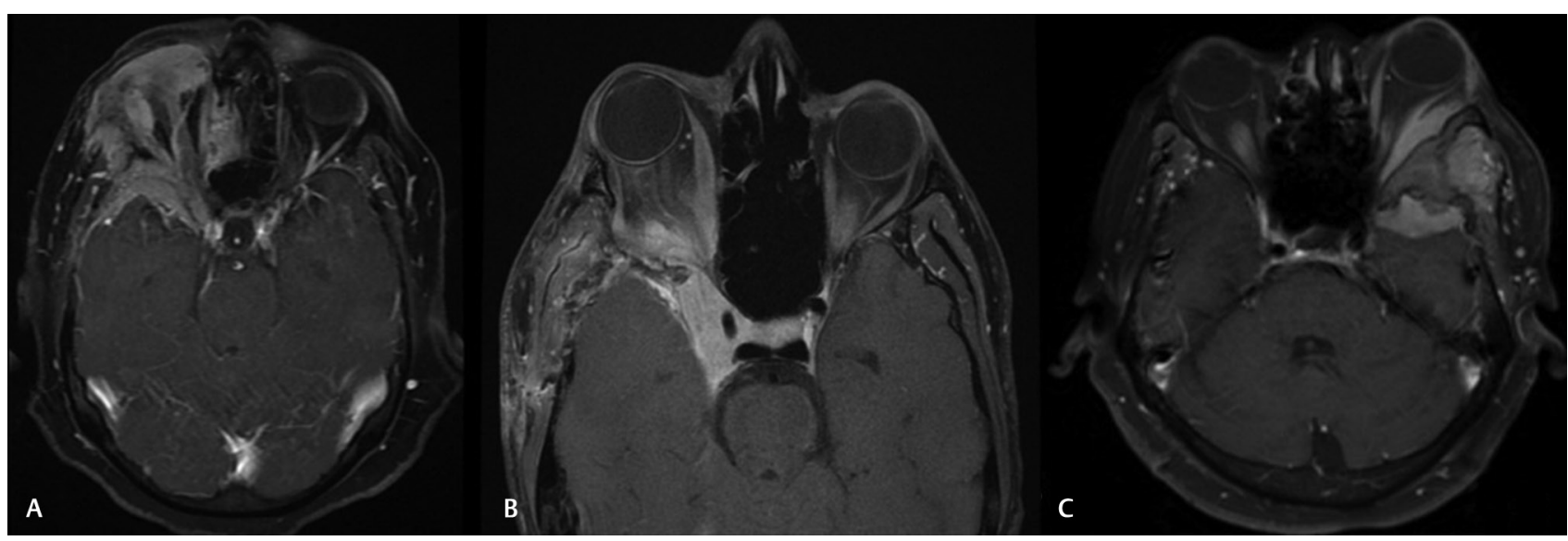

Fig. 2 Magnetic resonance orbital images of three patients with varying degrees of orbital extension. (A) Along the lateral wall under the periorbital and reaching up to the apex. (B) Tumor extending into the cavernous sinus. (C) Tumor reaching into the temporalis muscle and up to the subcutaneous plane over the zygoma.

as presented by Scarone et al. ${ }^{3}$ The distance from the most anterior aspect of the globe on a section including the lens to a line between the anterior tips of the frontal processes of the zygomas was calculated on a computed tomography/ magnetic resonance (CT/MR) image. The ratio between this measure in the affected eye and the same measure in the contralateral eye was defined as the EI.

All patients underwent frontotemporal craniotomy followed by extensive drilling of the greater wing of sphenoid and lateral orbital wall up to the apex of the orbit. Optic canal (OC) deroofing and anterior clinoidectomy was done routinely in all the 12 patients in the latter part of our series. The medial limits of the bony and dural removal were the superior orbital fissure (SOF) and the basal foraminas. In patients with no breach of periorbita, the tumor was stripped off the periorbita while preserving its integrity. In patients with tumor extension deep to the periorbita, the periorbita was opened widely and tumor decompression done without aggressive manipulation of the extraocular muscles and nerves. The resection cavity was filled with fat and temporalis muscle. Reconstruction of the orbital walls was not performed in any of our case. Radiotherapy was offered to all patients with significant residue, progressive residue, and patients with atypical meningiomas. Improvement in proptosis was assessed based on the first postoperative magnetic resonance imaging (MRI) study performed 3 to 6 months after the operation. Yearly MRI scans were done to assess recurrence and increase in size of residue if any.

Retrospective analysis of the orbital volume was calculated in all the 14 patients with proptosis using three-dimensional (3D) volume rendering assisted region-of-interest computation. In preoperative scans, the innermost orbital margins were manually plotted and the volume was analyzed using a free software. Postoperative margin delineation was a challenge as the lateral orbital margins were deficient. The innermost margin of the visible soft tissue was plotted in areas where the bone had been drilled out. Orbital volume assessment was not used to analyze visual outcome as it was felt that visual compromise is more related to optic nerve compromise at the $\mathrm{OC}$ and foramen.
Apart from patient demographics, the following variables were analyzed to predict the outcome: duration of symptoms, EI index, preoperative VA, extent of resection, and preand postoperative orbital volumes. Patient demographics were quantified using frequency statistics. Factors found to contribute significantly in predicting tumor recurrence were examined using Fisher's exact test for categorical variables and Student's $t$-test for continuous variables. Analysis was performed using Statistical Analysis System version 9.4. A $p$-value $<0.05$ was considered statistically significant.

\section{Results}

The demographic details of the 17 patients who met the inclusion criteria for this study are shown in -Table 1 . Patients' age ranged from 17 to 72 years (mean, 50.57 years; median, 50.0 years). Women represented 13 (76.4\%) of the entire study group. Duration of preoperative symptoms ranged from 1 to 90 months (mean, 33 months; median, 36 months). Patients were categorized into three groups based on the duration of symptoms: less than 2 years (5), 2 to 4 years (8), and more than 4 years (4). Proptosis (14/17; $82.3 \%)$ and visual impairment $(14 / 17 ; 82.3 \%)$ were the two most common presenting complaints followed by headache $(12 / 17 ; 70.1 \%)$. Four patients presented with numbness/paresthesia in one or more branches of the trigeminal nerve. Proptosis, as measured by the EI, was present in 14 of the 17 patients (82.3\%) on presentation. Visual impairment in the affected side was evident in 14 patients -2 of them having severe impairment (>6/30), 3 having moderate impairment (6/9-6/30), and 9 having mild impairment. The tumors were more often seen on the left side than the right (10:7). Gross total resection (GTR) could be achieved in only two patients $(11.8 \%)$ in this series. The remaining 15 patients $(88.2 \%)$ had subtotal resection (STR). The most common locations for residual tumor were the orbit, cavernous sinus (CS), SOF, and OC. Histologic analysis was consistent with World Health Organization (WHO) Grade I meningioma in 14 of 17 (84\%) tumors and WHO Grade II meningioma in the remaining 3 tumors (17.6\%). Mean follow-up time for the entire cohort 
Table 1 Clinical and demographic summary of all the patients in the present series

\begin{tabular}{|c|c|c|c|c|c|c|c|c|}
\hline Age & Sex & Presenting complaints & $\begin{array}{l}\text { Duration of } \\
\text { symptoms (mo) }\end{array}$ & $\begin{array}{l}\text { Extent of } \\
\text { resection }\end{array}$ & Histopathology & Radiation & Resurgery & $\begin{array}{l}\text { Follow-up } \\
\text { (mo) }\end{array}$ \\
\hline 52 & $\mathrm{~F}$ & Proptosis, vision, headache & 22 & STR & Atypical & RT & Yes & 38 \\
\hline 32 & $\mathrm{~F}$ & Proptosis, vision, headache & 34 & STR & Grade I & No & No & 36 \\
\hline 43 & $\mathrm{~F}$ & Proptosis, headache, vision & 12 & STR & Grade I & RT & No & 54 \\
\hline 64 & $\mathrm{~F}$ & Proptosis, vision, headache & 8 & STR & Grade I & No & No & 32 \\
\hline 60 & $\mathrm{~F}$ & Proptosis, vision, headache & 36 & STR & Atypical & RT & Yes & 68 \\
\hline 59 & M & Proptosis, headache & 54 & STR & Grade I & No & No & 72 \\
\hline 44 & $\mathrm{~F}$ & Vision, headache & 33 & GTR & Grade I & RT & No & 86 \\
\hline 49 & $\mathrm{~F}$ & Proptosis, headache & 22 & STR & Grade I & RT & No & 46 \\
\hline 72 & $\mathrm{~F}$ & Vision, headache & 18 & STR & Grade I & No & No & 56 \\
\hline 17 & $\mathrm{M}$ & Proptosis, vision & 26 & STR & Grade I & No & No & 68 \\
\hline 52 & $\mathrm{~F}$ & Proptosis, facial paresthesia, vision & 42 & STR & Grade I & No & No & 72 \\
\hline 40 & $\mathrm{~F}$ & Proptosis, vision, headache & 60 & STR & Grade I & RT & No & 48 \\
\hline 44 & $\mathrm{~F}$ & Vision, headache & 36 & STR & Grade I & No & No & 54 \\
\hline 69 & $\mathrm{~F}$ & Proptosis, vision, facial paresthesia & 45 & STR & Grade I & No & No & 62 \\
\hline 68 & $\mathrm{M}$ & $\begin{array}{l}\text { Proptosis, facial paresthesia, } \\
\text { headache }\end{array}$ & 52 & STR & Atypical & RT & Yes & 36 \\
\hline 41 & $\mathrm{~F}$ & Proptosis, vision & 38 & GTR & Grade I & No & No & 74 \\
\hline 54 & M & Proptosis, vision, facial paresthesia & 28 & STR & Grade I & RT & No & 54 \\
\hline
\end{tabular}

Abbreviations: F, female; GTR, gross total resection; M, male; mo, month; RT, radiotherapy; STR, subtotal resection.

Table 2 Orbital volume assessment and its influence on proptosis

\begin{tabular}{|c|c|c|c|c|c|}
\hline & Preoperative EI & $\begin{array}{l}\text { Orbital } \\
\text { volume }\left(\mathrm{cm}^{3}\right)\end{array}$ & $\begin{array}{l}\text { Postoperative } \\
\text { volume }\left(\mathrm{cm}^{3}\right)\end{array}$ & $\begin{array}{l}\text { Change in } \\
\text { orbital volume }\end{array}$ & Outcome \\
\hline 1 & 1.46 & 20.23 & 23.32 & 3.09 & Improved \\
\hline 2 & 1.26 & 21.52 & 23.67 & 2.15 & Static \\
\hline 3 & 1.04 & 22.67 & 23.78 & 1.11 & Static \\
\hline 4 & 1.27 & 21.22 & 24.43 & 3.21 & Improved \\
\hline 5 & 1.30 & 22.11 & 24.76 & 2.65 & Improved \\
\hline 6 & 1.18 & 21.12 & 23.78 & 2.66 & Improved \\
\hline 7 & 0.94 & 25.355 & 26.12 & 0.765 & Static \\
\hline 8 & 1.27 & 21.06 & 23.09 & 2.03 & Static \\
\hline 9 & 1.26 & 21.21 & 23.76 & 2.55 & Improved \\
\hline 10 & 1.21 & 21.09 & 22.32 & 1.23 & Static \\
\hline 11 & 1.18 & 22.21 & 24.32 & 2.11 & Improved \\
\hline 12 & 1.19 & 21.43 & 22.34 & 0.91 & Improved \\
\hline 13 & 1.43 & 20.23 & 22.56 & 2.33 & Improved \\
\hline 14 & 1.22 & 22.13 & 23.76 & 1.63 & Improved \\
\hline Mean & & 21.68 & 23.72 & 2.03 & \\
\hline
\end{tabular}

Abbreviation: El, exophthalmos index.

was 56.23 months. Postoperative imaging at 3- to 6-month follow-up visit was available for all the 17 patients.

The mean preoperative orbital volume was $21.68 \pm 3.2 \mathrm{~cm}^{3}$ and the mean postoperative orbital volume was $23.72 \pm 3.4 \mathrm{~cm}^{3}$. Orbital volume was significantly less in patients with higher EI. The mean increase in orbital volume was $2.03 \mathrm{~cm}^{3}$. However, reduction in orbital volume did not correlate with significant improvement in proptosis (-Table 2).

\section{Exophthalmos Outcome}

Postoperatively, proptosis improved in nine (64.3\%) and remained static in the rest five (35.7\%) of patients (- Table 3 ). None of our patients developed enophthalmos due to 
Table 3 Comparison of exophthalmos index (EI) preoperatively and at last follow-up on 14 patients who presented with proptosis

\begin{tabular}{|l|l|l|l|}
\hline Patient & $\begin{array}{l}\text { Preoperative } \\
\text { El }\end{array}$ & $\begin{array}{l}\text { El at } \\
\text { follow-up }\end{array}$ & Outcome \\
\hline 1 & 1.46 & 1.23 & Improved \\
\hline 2 & 1.26 & 1.20 & Static \\
\hline 3 & 1.04 & 0.97 & Static \\
\hline 4 & 1.27 & 1.01 & Improved \\
\hline 5 & 1.30 & 1.02 & Improved \\
\hline 6 & 1.18 & 1.03 & Improved \\
\hline 7 & 0.94 & 0.94 & Static \\
\hline 8 & 1.27 & 1.23 & Static \\
\hline 9 & 1.26 & 1.03 & Improved \\
\hline 10 & 1.21 & 1.25 & Static \\
\hline 11 & 1.18 & 1.02 & Improved \\
\hline 12 & 1.19 & 0.97 & Improved \\
\hline 13 & 1.43 & 1.25 & Improved \\
\hline 14 & 1.22 & 0.97 & Improved \\
\hline Mean & 1.22 & 1.08 & \\
\hline
\end{tabular}

excessive bony or soft tissue decompression. It was observed that improvement in proptosis was better when the decompression of the orbital walls, especially the lateral orbital, was adequately performed. This was well appreciated in two of our patients who underwent resurgery for recurrence and the lateral orbital wall drilling was performed extensively (-Fig. 3). We did not observe any close relation between periorbital removal and improvement in proptosis. Since bony or plate reconstruction was not performed in any of our patients, its influence on proptosis could not be assessed.
Table 4 Visual status before and after surgery at last follow-up in the 14 patients who presented with visual deficits

\begin{tabular}{|l|l|l|}
\hline & Preoperative vision & Outcome \\
\hline 1 & Mild (6/6-6/9) & Improved \\
\hline 2 & Mild (6/6-6/9) & Static \\
\hline 3 & Moderate (6/9-6/30) & Static \\
\hline 4 & Mild & Improved \\
\hline 5 & Moderate $(6 / 9-6 / 30)$ & Static \\
\hline 6 & Severe $(6 / 60$ or worse) & Deteriorated \\
\hline 7 & Mild $(6 / 6-6 / 9)$ & Static \\
\hline 8 & Mild $(6 / 6-6 / 9)$ & Static \\
\hline 9 & Severe $(6 / 60$ or worse) & Deteriorated \\
\hline 10 & Mild $(6 / 6-6 / 9)$ & Static \\
\hline 11 & Mild $(6 / 6-6 / 9)$ & Static \\
\hline 12 & Mild (6/6-6/9) & Improved \\
\hline 13 & Moderate (6/9-6/30) & Improved \\
\hline 14 & Mild (6/6-6/9) & Static \\
\hline
\end{tabular}

Note: Mild (6/6-6/9 with intact visual field [VF]), moderate (6/9-6/30 with or without VF loss), or severely impaired (6/60 or worse).

\section{Visual Outcome}

Four patients (28.6\%) improved in vision following surgery. Vision remained static in eight patients (57.1\%) and vision deteriorated in two (14.3\%) in the postoperative period (-Table 4). The two patients who deteriorated had primary optic atrophy and extremely poor vision preoperatively (restricted to hand movements). All the four patients who improved postoperatively were operated in the latter part of series where we used to perform OC deroofing and anterior clinoid process (ACP) routinely, irrespective of their involvement in imaging (-Fig. 4).

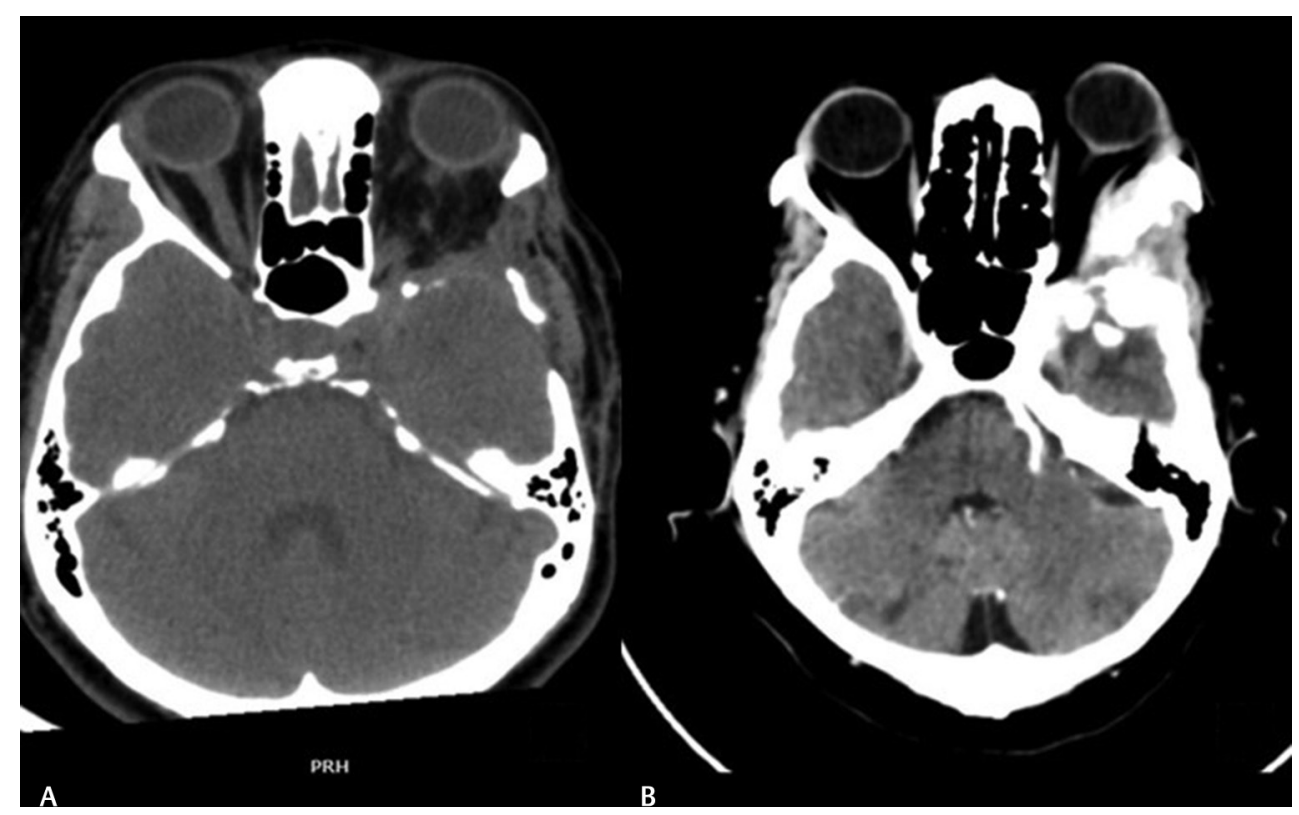

Fig. 3 Postoperative computed tomography images of a patient. (A) Following extensive bony removal around the lateral orbital wall. (B) Following inadequate bone removal of the lateral wall sphenoid wing. 


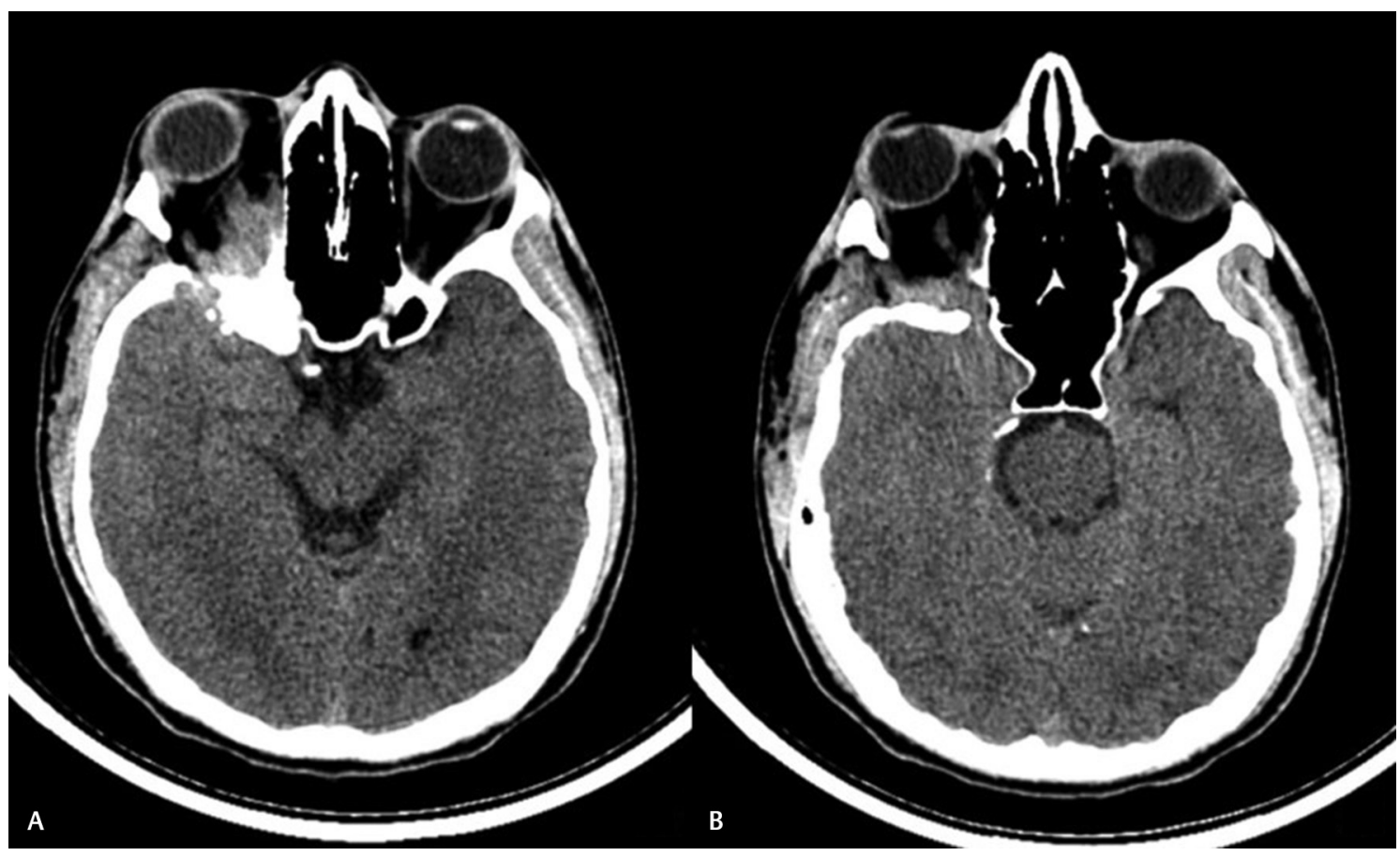

Fig. 4 Postoperative computed tomography images of a patient. (A) Following inadequate bony removal around the optic canal (OC) and anterior clinoid process (ACP). (B) Following removal of the ACP and OC deroofing.

\section{Complications}

We did not have any mortality in our series. One of our patients had to be reexplored for an extradural hematoma. New onset oculomotor palsy was noticed in three patients (17.6\%), which persisted for nearly 6 months in two. Disabling facial hyperesthesia over the trigeminal distribution was seen in two patients, which was partially controlled with medications. Restricted ocular motility due to mechanical causes and not related to any nerve palsy was seen in six patients (35.3\%). However, these disturbances improved with time.

\section{Recurrence and Radiation Therapy}

At mean follow-up of 3 years, of the 15 patients with residual lesions, the tumor showed progression in 10 (58.9\%) and remained stable in the remaining 5. Three of these 10 patients had symptomatic recurrence warranting repeat surgery (17.4\%), which was followed by radiotherapy. All the other seven patients were advised radiotherapy of whom only five completed it. All the three symptomatic recurrences requiring surgery occurred in patients with Grade II meningiomas. Patients with small residual/stable recurrences were kept under a close follow-up with serial imaging.

\section{Outcome Predictors}

Patients with relatively better preoperative vision fared better postoperatively as did patients with a symptom history of less than 2 years. However, we felt that liberal bony decompression of the lateral wall of orbit, OC, and ACP removal helps in visual improvement and reduction in proptosis. As the total number of patients in the series is small, statistical significance was difficult to obtain for any of the factors ( - Tables 5 and 6 ).

\section{Discussion}

SOMs are rare intracranial tumors, accounting for 2.3 to $11.8 \%$ of all intracranial meningiomas in literature. ${ }^{1-3}$ Despite their benign histopathology, these tumors pose considerable surgical challenges mainly because of the difficulty to achieve radical resection. ${ }^{3-6}$ However, the management philosophy has evolved over the years. Aggressive radical resection has been replaced by a less radical surgical strategy with more encouraging results. ${ }^{5-14}$ Currently, the primary goal in the surgical treatment aims at restoring visual function and reduction in proptosis, rather than radical complete resection.

Unlike most of the other variants of meningiomas, SOMs are creepy infiltrative lesions. SOMs essentially differ from other sphenoid wing meningiomas in two characteristic radiological features-an intraosseous component and an orbital/periorbital component. .,2, $, 7,15$ The bony involvement is characterized by hyperostosis of the sphenoid wing, both lesser and greater wings, orbital roof, SOF, OC, and the ACP. The orbital component can vary from a small intraorbital extension to extensive periorbital and intraconal extensions. The dural component in SOMs, unlike in other sphenoid wing meningiomas, involves carpet-like extensions along the sphenoid wing, CS, and temporal convexity. The intradural extension may result in temporal and subfrontal extensions similar to other sphenoid wing meningiomas. The extradural growth may manifest as tumor infiltrations into the infratemporal fossa and the temporal muscle..$^{10,16,17}$

\section{Symptomatology}

Proptosis (45-100\%) and progressive visual deterioration (30-77\%) are the two most common presenting 
Table 5 Predictors of visual outcome following surgery

\begin{tabular}{|c|c|c|c|c|c|}
\hline \multirow{2}{*}{$\begin{array}{l}\text { Total number of patients } \\
\text { with visual symptoms (14) }\end{array}$} & \multirow[t]{2}{*}{ Improved (4) } & \multirow[t]{2}{*}{ Static (8) } & \multirow[t]{2}{*}{ Worsened (2) } & \multicolumn{2}{|c|}{ Univariate analysis } \\
\hline & & & & $p$-Value & OR \\
\hline Age in years (mean $\pm S D$ ) & $51.48 \pm 10.85$ & $48.43 \pm 12.35$ & $50.48 \pm 11.25$ & & \\
\hline \multicolumn{4}{|l|}{ Sex } & 0.501 & 5 \\
\hline Male (3) & 1 & 1 & 1 & & \\
\hline Female (11) & 3 & 7 & 1 & & \\
\hline \multicolumn{4}{|l|}{ Vision } & 0.007 & \\
\hline Mild & 3 & 6 & & & 0.008 \\
\hline Moderate & 1 & 2 & & & \\
\hline Severe & & & 2 & & \\
\hline \multicolumn{4}{|l|}{ Extent of resection } & \multirow[t]{3}{*}{0.694} & \multirow[t]{3}{*}{0.84} \\
\hline GTR (2) & 1 & 1 & & & \\
\hline STR (12) & 3 & 7 & 2 & & \\
\hline \multicolumn{4}{|l|}{ Optic canal deroofing } & \multirow[t]{3}{*}{0.334} & \multirow[t]{3}{*}{0.377} \\
\hline Done (12) & 4 & 8 & & & \\
\hline Not done (2) & & 2 & & & \\
\hline \multicolumn{4}{|l|}{ Preoperative symptoms } & \multirow[t]{4}{*}{0.512} & \multirow[t]{4}{*}{1.19} \\
\hline $0-2$ years $(4)$ & 2 & 1 & 1 & & \\
\hline $2-4$ years $(8)$ & 2 & 5 & 1 & & \\
\hline$>4$ years $(2)$ & & 2 & & & \\
\hline
\end{tabular}

Abbreviations: GTR, gross total resection; OR, odds ratio; SD, standard deviation; STR, subtotal resection.

Table 6 Predictors of outcome of proptosis following surgery

\begin{tabular}{|c|c|c|c|c|c|}
\hline \multirow{2}{*}{$\begin{array}{l}\text { Total number of patients } \\
\text { with proptosis (14) }\end{array}$} & \multirow[t]{2}{*}{ Improved (9) } & \multirow[t]{2}{*}{ Static (5) } & \multirow[t]{2}{*}{ Worsened (0) } & \multicolumn{2}{|c|}{ Univariate analysis } \\
\hline & & & & $p$-Value & OR \\
\hline \multicolumn{4}{|l|}{ Age } & & \\
\hline Age in years (mean $\pm S D$ ) & $44.23 \pm 10.22$ & $46.12 \pm 12.32$ & 0 & & \\
\hline \multicolumn{4}{|l|}{ Sex } & 0.796 & 0.75 \\
\hline Male (3) & 2 & 1 & 0 & & \\
\hline Female (11) & 6 & 4 & 0 & & \\
\hline \multicolumn{4}{|l|}{ Extent of resection } & \multirow[t]{3}{*}{0.922} & \multirow[t]{3}{*}{0.875} \\
\hline GTR (2) & 2 & 1 & 0 & & \\
\hline STR (12) & 7 & 4 & 0 & & \\
\hline \multicolumn{4}{|l|}{ Optic canal deroofing } & 0.333 & 0.377 \\
\hline Done (12) & 4 & 8 & 0 & & \\
\hline Not done (2) & & 2 & 0 & & \\
\hline \multicolumn{4}{|l|}{ Preoperative symptoms } & \multirow[t]{4}{*}{0.122} & \multirow[t]{4}{*}{0.073} \\
\hline $0-2$ years $(4)$ & 3 & 1 & & & \\
\hline $2-4$ years $(8)$ & 6 & 2 & & & \\
\hline$>4$ years $(2)$ & & 2 & & & \\
\hline
\end{tabular}

Abbreviations: GTR, gross total resection; OR, odds ratio; SD, standard deviation; STR, subtotal resection. 
complaints of patients with SOM. ${ }^{5,7,8,18,19}$ Guiot et al divided SOMs into two categories. ${ }^{20,21}$ First, the pterional or external variety, which is associated with early exophthalmos and may cause decreased VA in the late stage. Second, the internal variety, which may cause optic nerve compression and visual deficits at presentation. Cranial nerve deficits, temporal swelling, and headache or retroorbital pain are other common symptoms of SOM. ${ }^{5-9,18,22}$

Reasons for proptosis are multifactorial. ${ }^{14}$ In addition to the osseous invasion of the tumor in the orbital walls, mass effect due to the intraorbital soft tissue component of the tumor and the reduction in venous drainage from the orbit result in proptosis. ${ }^{3,15,23}$ Scarone et al observed that radiological evidence of exophthalmos is always present even if it is not obvious clinically. ${ }^{3}$ Visual impairment is directly related to the tumor invasion into the orbit, especially in the orbital apex and OC region. ${ }^{8,24}$ Oculomotor nerve and trigeminal nerve involvements usually indicate extension of the tumor into the CS, SOF, and other basal foramina. Headache is seldom due to raised intracranial pressure as these lesions have a propensity to spread along the convexity and basal dura rather than into the brain parenchyma. The presenting symptoms in our series correspond with other published series except for the higher number of patients with visual impairment on presentation. This probably is related to the delay in presentation and larger size of tumor at presentation.

\section{Radiology}

SOMs need to be differentiated from orbital meningiomas and sphenoid wing meningiomas. ${ }^{25,26}$ Combination of extensive bony hyperostosis and orbital extension are distinct characteristic imaging features of SOM. The exact cause and mechanism of the bony hyperostosis is unclear and is a matter of debate. The current consensus is that it represents direct tumor invasion of the bone as several studies have confirmed histological tumor invasion in resected osseous specimens. $3.23,27,28$ SOMs thus qualify as tumors of the interperiosteodural concept. ${ }^{18}$ This indicates that hyperostosis essentially is a part of the neoplastic process and GTR implies removal of the entire affected bone, which is a formidable surgical challenge. ${ }^{1,29,30}$ Signal intensity changes in SOMs on MRI are similar to other meningiomas. SOMs, however, tend to breach the pia of the brain parenchyma, and the tumor brain interface is often not distinct on MR images. MR images may also reveal the increased vascularity of these tumors, essentially from external carotid supply.

\section{Management}

Surgery is the first line of management. The surgical technique needs to be customized based on the extent of the lesion. Standard frontotemporal craniotomy combined with additional orbital or zygomatic osteotomies in selected cases is the preferred approach by most authors.,3,5,12,16,22,31 In addition, most authors concur that tumor invasion to the SOF as well as extension into the CS should constitute the limiting factors of radical resection and that the integrity of the periorbita should not be violated unless there is a discrete tumor involvement.,3,10,12,14 Two aspects of the surgical technique remain controversial: The first debate involves the removal of ACP as an integral routine step in surgery. Involvement of ACP is seen in 5 to $56 \%$ of the cases, ${ }^{1-3,8,9,11,26}$ and hence few authors believe that anterior clinoidectomy and OC deroofing need be done only in affected patients. ${ }^{2}$ We share the opposite view and believe that ACP removal and OC deroofing improves visual outcome and should be included as a routine step in surgery. ${ }^{3,6,14,16,27}$ Selective rigid orbital reconstruction is another controversial surgical strategy. Multiple techniques and materials have been described for orbital reconstruction using both autologous and synthetic implants. Some authors favor a rigid reconstruction in all cases to avoid enophthalmos, ocular paresis, poor cosmesis, pulsatile exophthalmos, and pseudomeningocele.,19 Others feel that reconstruction is unnecessary regardless of the extent of orbital wall removal. They argues that reconstruction is neither necessary for cosmesis nor for preventing pulsatile enopthalmos. ${ }^{6,10,12,32}$ A third view is that rigid reconstruction is necessary to achieve a good cosmetic result only if the periorbita is widely violated. ${ }^{2,31}$ In our small series of 17 cases, we have achieved reasonable cosmetic results without any rigid reconstruction.

\section{Degree of Resection}

Although Simpson's Grade I resection with minimal morbidity remains the primary treatment goal, it is often impossible to accomplish without causing severe morbidity. ${ }^{1,7,9}$ Reported rates of GTR vary from 0 to $70 \%,{ }^{2,3,7,11,16}$ and we could achieve GTR in only two of our patients. We believe in the general consensus that surgery should be "symptomoriented." $3,5,6,8$ Customized tumor resection helps to maximize VA outcomes and to improve proptosis in comparison to GTR. Decompression of the orbital walls, orbital apex, and OC should be aggressive. Resection in and around SOF, CS, and under the periorbita should be conservative.

\section{Recurrence}

Residual disease is common, but published recurrence rates for surgically resected SOMs, with and without radiation, ranges from 0 to $71 \%{ }^{1,7,16,19}$ The evolution of residual tumor is highly variable, with very slow regrowth in most cases or complete stability for years. The rate of SOM progression is not as rapid as that of malignant meningioma, but is comparable to that of other WHO Grade I meningiomas. Younger age at presentation (40s vs. 50 s) was the only factor significantly associated with recurrence in Freeman's cohort. ${ }^{8}$ Ho et al found that SOMs had a higher number of $1 \mathrm{p}$ and $6 \mathrm{q}$ deletions and this subtype more frequently progressed after STR. ${ }^{33}$ Long-term medical follow-up is essential, because the majority of recurrences appeared 6 years after the surgery. ${ }^{10}$ Tumor recurrence is significantly influenced by the extent of meningioma resection. Mariniello et al reported that the recurrence rate was greater after Simpson's Grades III and IV resection than after Grade I resection. ${ }^{28}$ Surgical strategy aimed at maximal tumor resection with functional preservation provides an estimated 5- and 10-year progression-free survival (PFS) of 75 and $49 \%$, respectively. ${ }^{10,14}$ We share Gonen et al's view that the rate of growth of residual disease is slow. ${ }^{2}$ Despite a residual tumor in $48.2 \%$ of the cases, progression of residual tumor was slow and limited to $7.7 \%$. 


\section{Outcome and Outcome Predictors}

Literature reports on proptosis improvement vary from 60 to $96 \%, 5,5,8,9,16$ The main factors that influence postoperative exophthalmos regression are still not clear. Preoperative duration of symptoms, extent of orbital wall removal, especially the lateral wall, and the integrity of the periorbita have been postulated as leading factors. ${ }^{9,10}$ While some authors believe that periorbital removal is necessary for adequate improvement in proptosis, ${ }^{6,9,14,15}$ others like Oya et al prefer to maintain the periorbita for functional preservation. ${ }^{18}$ We believe in the middle path proposed by Nagahama et al, which is to tailor the resection-resect the invaded periorbita but do not perform reconstruction if the residual tumor is large. ${ }^{12}$ Although we believe that liberal lateral orbital wall removal up to the apex helps in proptosis reduction, we could not find any statistically significant relation in our series.

Visual improvement after SOM surgery ranges from 17 to 77\%., 7,12,1631,32 As in Terrier's series, in our series too, none of the patients' characteristics-age, duration of symptoms, extent of proptosis, or surgical procedure-contributed to predicting the visual outcome. ${ }^{9}$ Gonen et al reported that preoperative visual deficit and $O C$ involvement are significant parameters affecting favorable change in visual function after resection of SOM. ${ }^{2}$ We too strongly believe that decompression of the optic nerve is a mandatory step in SOM surgery and our findings support the concept that visual outcome is related to the extent of optic nerve decompression, rather than the extent of tumor resection. We observed that postoperatively vision worsened in two of our patients who had severe preoperative visual deficits. The probable reasons for this decline include intraoperative handling of an already compromised optic nerve, vascular compromise, and thermal injury during OC drilling. We believe that all orbital surgeons should be aware of this possible complication and need to be extra cautious in patients with severely affected vision.

\section{Orbital Volume and Proptosis}

Orbital volume assessment is important in orbital reconstruction, especially in orbital fractures and craniofacial anomalies. ${ }^{34,35}$ Reconstruction of the bony orbit is a challenge, following decompressive orbital surgeries. Several studies have recently been published on orbital volume assessment using 3D volumetric computational techniques. ${ }^{34,35}$ Their role in prognostication of proptosis following surgery for orbital pathologies like tumors have not been reported extensively. Current focus is more on restoration of orbital volume to improve aesthetics following surgery. Our study focused on the prognostic role of increase in orbital volume in improving proptosis. Our findings were not significant probably because of the small number of patients in the study.

\section{Complications}

Complications following SOM resection may include new onset cranial nerve deficits and ocular paresis due to mechanical restriction. Improvement in these new onset symptoms are often delayed, variable, and unpredictable. ${ }^{10,18}$ Restricted ocular motility due to mechanical causes usually happens in patients where aggressive attempt is made to free the tumor attached to the intraocular muscles. Keeping the periorbita open and being conservative with tumor adherent to the intraocular contents reduce this complication. New onset oculomotor palsy and trigeminal dysfunction can similarly be minimized by a conservative decompression around the SOF, CS, and basal foraminas.

\section{Radiation Therapy}

The role or timing of radiotherapy in SOM is controversial. Initially restricted to WHO Grade II and Grade III tumors, recent studies support the use of radiation therapy for subtotally resected Grade I meningiomas, demonstrating an overall and PFS advantage over surgery alone., ${ }^{3,6,36}$ Stereotactic radiosurgery (SRS) alone or in conjunction with fractionated intensity-modulated radiotherapy may be of particular benefit in treating SOMs. ${ }^{34}$ The optimal timing of radiation treatment (immediately after surgery or at recurrence) is still debated. Our current strategy is to recommend immediate postoperative radiotherapy for all Grade II and III meningiomas and patients with significant residue.

\section{Conclusion}

SOMs constitute a rare subgroup of skull base meningiomas that pose considerable surgical challenges. A surgical strategy aimed at safe maximal resection rather than aggressive GTR provides favorable outcome with less morbidity. Adequate bony decompression of the orbital walls and OC provides satisfactory improvement in proptosis and vision. Residual disease is common, but the risk of symptomatic recurrence is low especially when combined with adjuvant radiotherapy. Visual outcome is likely to be poor in patients presenting with severely compromised vision.

\section{Limitations}

The small number of patients in our series limits the possibility of arriving at any statistically significant conclusion with regard to predictors of outcome.

\section{Funding}

None.

\section{Conflict of Interest}

None declared.

\section{References}

1 Bikmaz K, Mrak R, Al-Mefty O. Management of bone-invasive, hyperostotic sphenoid wing meningiomas. J Neurosurg 2007;107(5):905-912

2 Gonen L, Nov E, Shimony N, Shofty B, Margalit N. Sphenoorbital meningioma: surgical series and design of an intraoperative management algorithm. Neurosurg Rev 2018;41(1):291-301

3 Scarone P, Leclerq D, Héran F, Robert G. Long-term results with exophthalmos in a surgical series of 30 sphenoorbital meningiomas. Clinical article. J Neurosurg 2009;111(5):1069-1077

4 Schick U, Bleyen J, Bani A, Hassler W. Management of meningiomas en plaque of the sphenoid wing. J Neurosurg 2006;104(2):208-214 
5 Boari N, Gagliardi F, Spina A, Bailo M, Franzin A, Mortini P. Management of spheno-orbital en plaque meningiomas: clinical outcome in a consecutive series of 40 patients. $\mathrm{Br} \mathrm{J}$ Neurosurg 2013;27(1):84-90

6 Ringel F, Cedzich C, Schramm J. Microsurgical technique and results of a series of 63 spheno-orbital meningiomas. Neurosurgery 2007;60(4(Suppl 2) :214-221, discussion 221-222

7 Honig S, Trantakis C, Frerich B, Sterker I, Kortmann R-D, Meixensberger J. Meningiomas involving the sphenoid wing outcome after microsurgical treatment-a clinical review of 73 cases. Cent Eur Neurosurg 2010;71(4):189-198

8 Freeman JL, Davern MS, Oushy S, et al. Spheno-orbital meningiomas: a 16-year surgical experience. World Neurosurg 2017;99:369-380

9 Terrier L-M, Bernard F, Fournier H-D, et al. Spheno-orbital meningiomas surgery: multicenter management study for complex extensive tumors. World Neurosurg 2018;112: e145-e156

10 Talacchi A, De Carlo A, D’Agostino A, Nocini P. Surgical management of ocular symptoms in spheno-orbital meningiomas. Is orbital reconstruction really necessary? Neurosurg Rev 2014;37(2):301-309, discussion 309-310

11 Bowers CA, Sorour M, Patel BC, Couldwell WT. Outcomes after surgical treatment of meningioma-associated proptosis. J Neurosurg 2016;125(3):544-550

12 Nagahama A, Goto T, Nagm A, et al. Spheno-orbital meningioma: surgical outcomes and management of recurrence. World Neurosurg 2019;126:e679-e687

13 Terpolilli NA, Ueberschaer M, Niyazi M, et al. Long-term outcome in orbital meningiomas: progression-free survival after targeted resection combined with early or postponed postoperative radiotherapy. J Neurosurg 2019;:1-11

14 Kiyofuji S, Casabella AM, Graffeo CS, Perry A, Garrity JA, Link MJ. Sphenoorbital meningioma: a unique skull base tumor. Surgical technique and results. J Neurosurg 2019;:1-8

15 Saeed P, van Furth WR, Tanck M, et al. Natural history of spheno-orbital meningiomas. Acta Neurochir (Wien) 2011; 153(2):395-402

16 Shrivastava RK, Sen C, Costantino PD. Della Rocca R. Sphenoorbital meningiomas: surgical limitations and lessons learned in their long-term management. J Neurosurg 2005; 103(3):491-497

17 Forster M-T, Daneshvar K, Senft C, Seifert V, Marquardt G. Sphenoorbital meningiomas: surgical management and outcome. Neurol Res 2014;36(8):695-700

18 Oya S, Sade B, Lee JH. Sphenoorbital meningioma: surgical technique and outcome. J Neurosurg 2011;114(5):1241-1249

19 Sandalcioglu IE, Gasser T, Mohr C, Stolke D, Wiedemayer $\mathrm{H}$. Spheno-orbital meningiomas: interdisciplinary surgical approach, resectability and long-term results. J Craniomaxillofac Surg 2005;33(4):260-266

20 Derome PJ, Guiot G. Bone problems in meningiomas invading the base of the skull. Clin Neurosurg 1978;25:435-451
21 Pompili A, Derome PJ, Visot A, Guiot G. Hyperostosing meningiomas of the sphenoid ridge-clinical features, surgical therapy, and long-term observations: review of 49 cases. Surg Neurol 1982;17(6):411-416

22 Cannon PS, Rutherford SA, Richardson PL, King A, Leatherbarrow $B$. The surgical management and outcomes for spheno-orbital meningiomas: a 7-year review of multi-disciplinary practice. Orbit 2009;28(6):371-376

23 Mirone G, Chibbaro S, Schiabello L, Tola S, George B. En plaque sphenoid wing meningiomas: recurrence factors and surgical strategy in a series of 71 patients. Neurosurgery 2009; 65(6, Suppl) :100-108, discussion 108-109

24 Zhi M, Girvigian MR, Miller MJ, et al. Long-term outcomes of newly diagnosed resected atypical meningiomas and the role of adjuvant radiotherapy. World Neurosurg 2019;122: e1153-e1161

25 Cushing $\mathrm{H}$. The cranial hyperostoses produced by meningeal endotheliomas. Arch NeurPsych 1922;8(2):139-154

26 Castellano F, Guidetti B, Olivecrona H. Pterional meningiomas en plaque. J Neurosurg 1952;9(2):188-196

27 Roser F, Nakamura M, Jacobs C, Vorkapic P, Samii M. Sphenoid wing meningiomas with osseous involvement. Surg Neurol 2005;64(1):37-43, discussion 43

28 Mariniello G, Maiuri F, Strianese D, et al. Spheno-orbital meningiomas: surgical approaches and outcome according to the intraorbital tumor extent. Zentralbl Neurochir 2008;69(4):175-181

29 Maschke S, Martínez-Moreno M, Micko A, et al. Challenging the osseous component of sphenoorbital meningiomas. Acta Neurochir (Wien) 2019;161(11):2241-2251

30 Alzhrani G, Couldwell W. Bony hyperostosis recurrence after complete resection of sphenoorbital meningioma. Cureus 2017;9(8):e1540

31 DeMonte F, Tabrizi P, Culpepper SA, Suki D, Soparkar CNS, Patrinely JR. Ophthalmological outcome after orbital entry during anterior and anterolateral skull base surgery. J Neurosurg 2002;97(4):851-856

32 Yannick N, Patrick F, Samuel M, et al. Predictive factors for visual outcome after resection of spheno-orbital meningiomas: a long-term review. Acta Ophthalmol 2012;90(8):e663-e665

33 Ho C-Y, Mosier S, Safneck J, et al. Genetic profiling by single-nucleotide polymorphism-based array analysis defines three distinct subtypes of orbital meningioma. Brain Pathol 2015;25(2):193-201

34 Shyu VBH, Hsu CE, Chen CH, Chen CT. 3D-assisted quantitative assessment of orbital volume using an open-source software platform in a Taiwanese population. PLoS One 2015;10(3): e0119589, 10.1371/journal.pone.0119589

35 Kwon J, Barrera JE, Most SP. Comparative computation of orbital volume from axial and coronal CT using three-dimensional image analysis. Ophthal Plast Reconstr Surg 2010;26(1):26-29

36 Gorman L, Ruben J, Myers R, Dally M. Role of hypofractionated stereotactic radiotherapy in treatment of skull base meningiomas. J Clin Neurosci 2008;15(8):856-862 